Rev Bras Psiquiatr 2002;24(2):102

\title{
Replica à carta "Correlação entre transtornos neuropsiquiátricos e infecção estreptocócica"
}

Li com interesse a correspondência enviada por Teixeira-Jr. Vale ressaltar que os critérios para admitir auto-imunidade não são minhas considerações, mas sim propostos por Archelos \& Hartung, ${ }^{1}$ quando discutem o caráter patogênico ou não dos auto-anticorpos. Outro ponto que gostaria de salientar é que, embora grande parte dessa pesquisa esteja atualmente dirigida à relação do transtornos psiquiátricos e da infecção estreptocócica, a hipótese de um possível transtorno obsessivo-compulsivo e/ou síndrome de Tourette (TOC/ST) de base imunológica não pode, nem deve, ser restringida a esse tipo de associação.

Quanto ao aspecto central do comentário - "ênfase nos autoanticorpos" e negligência do processo celular -, dois são os motivos para isto. Primeiro, como mencionado no artigo, vários aspectos podem ser mencionados, mas o trabalho foi dirigido aos fenômenos considerados mediados por anticorpos. Isto é: as evidências sugerem que, se existe um substrato imunológico mediando os sintomas neuropsiquiátricos nesses transtornos, ele conta com a participação de anticorpos. Dessa maneira, é necessário primeiramente demonstrar o papel patogênico desses anticorpos, como mencionado por Teixeira-Jr., objetivo dos estudos que têm sido realizados na área.

Segundo, mesmo após ter sido demonstrada a "patogenici-

\section{Referências}

1. Archelos JJ, Hartung HP. Pathogenic role of autoantibodies in neurological diseases. Trends Neurosci 2000;23:317-27.

2. Guilherme L, Cunha-Neto E, Coelho V, Snitcowsky R, Pomerantzeff PM, Assis RV, et al. Human heart-infiltrating T-cell clones from rheumatic heart disease patients recognize both streptococcal and cardiac proteins. Circulation 1995;92(3):415-20. dade" desses auto-anticorpos, teremos de compreender qual é o processo imunológico que estaria modulando esse tipo de resposta. Até o momento, as pesquisas sugerem que o braço da resposta celular está presente em todas as doenças autoimunes. Isso inclusive pode ser demonstrado por trabalho de importância realizado em nosso meio, na cardite reumática. ${ }^{2}$ No entanto, o grande impasse determinado pelo conceito de PANDAS está no caráter não "degenerativo" do processo, diferentemente do observado em todos os quadros auto-imunes.

Ainda que de maneira especulativa, baseada nos resultados preliminares dos estudos longitudinais desses pacientes com TOC/ST imunológico, é possível que estejamos frente a um processo imunológico independente de células $\mathrm{T}$, o que, se confirmado, justificaria os resultados contraditórios obtidos nesse campo de investigação. Nesse modelo, o ingresso dos auto-anticorpos no sistema nervoso central poderia acontecer devido a células B, T independentes, ativadas por antígenos classe- $1 .{ }^{3}$ Estudo para testagem dessa hipótese está sendo iniciado

Marcos T Mercadante Programa de Pós-Graduação em Distúrbios do Desenvolvimento Universidade Presbiteriana Mackenzie

3. Montes CL, Zuniga EI, Vazquez J, Arce C, Gruppi A. Trypanosoma cruzi mitochondrial malate dehydrogenase triggers polyclonal B-cell activation. Clin Exp Immunol 2002;127:27-36. 